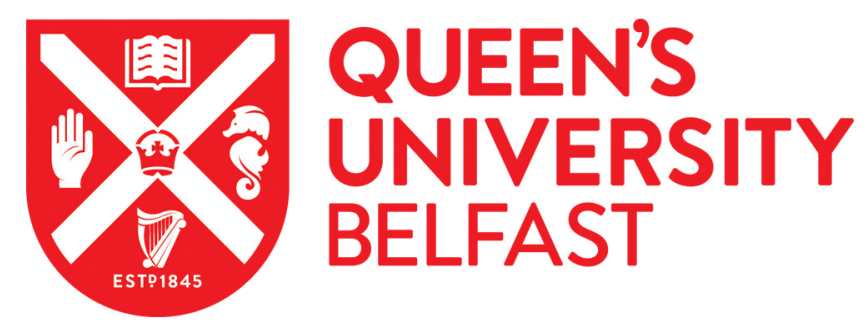

\title{
Efficacy of instant hand sanitizers against foodborne pathogens compared to hand washing with soap and water in food preparation settings: a systematic review
}

Foddai, A. C. G., Grant, I. R., \& Dean, M. (2016). Efficacy of instant hand sanitizers against foodborne pathogens compared to hand washing with soap and water in food preparation settings: a systematic review. Journal of Food Protection, 79(6), 1040-1054. https://doi.org/10.4315/0362-028X.JFP-15-492

Published in:

Journal of Food Protection

Document Version:

Peer reviewed version

Queen's University Belfast - Research Portal:

Link to publication record in Queen's University Belfast Research Portal

Publisher rights

Copyright 2016 Ingenta.

\section{General rights}

Copyright for the publications made accessible via the Queen's University Belfast Research Portal is retained by the author(s) and / or other copyright owners and it is a condition of accessing these publications that users recognise and abide by the legal requirements associated with these rights.

\section{Take down policy}

The Research Portal is Queen's institutional repository that provides access to Queen's research output. Every effort has been made to ensure that content in the Research Portal does not infringe any person's rights, or applicable UK laws. If you discover content in the Research Portal that you believe breaches copyright or violates any law, please contact openaccess@qub.ac.uk. 
1 Running title: Efficacy of hand sanitizers in food preparation setting

4 Efficacy of instant hand sanitizers against foodborne pathogens compared to

5 hand washing with soap and water in food preparation settings: a systematic 6 review

8 Antonio C.G. Foddai ${ }^{1}$, Irene R. Grant ${ }^{2}$ and Moira Dean ${ }^{2 *}$

$11{ }^{1}$ Department of Life Sciences, School of Health and Life Sciences, Glasgow 12 Caledonian University, Cowcaddens Road, Glasgow, G4 OBA, Scotland, United 13 Kingdom

$14{ }^{2}$ Institute for Global Food Security, School of Biological Sciences, Queen's University 15 Belfast, Belfast BT9 5BN, Northern Ireland, United Kingdom

*Author for correspondence. Tel: +44 289097 656, E-mail: $\underline{\text { moira.dean@qub.ac.uk }}$

21 Key words: Handwashing, hand sanitizers, foodborne pathogens, food settings, soiled hands 
ABSTRACT

Hands can be a vector for transmitting pathogenic microorganisms to foodstuffs and drinks, and to the mouths of susceptible hosts. Hand washing is the primary barrier to prevent transmission of enteric pathogens via cross-contamination from infected persons. Conventional hand washing involves the use of water, soap and friction to remove dirt and microorganisms. Over recent years there has been an increasing availability of hand sanitizing products for use when water and soap are unavailable.

The aim of this systematic review was to collate scientific information on the efficacy of hand sanitizers compared to hand washing with soap and water for the removal of foodborne pathogens from the hands of food handlers. An extensive literature search was carried out using three electronic databases - Web of Science, Scopus and PubMed. Twenty-eight scientific publications were ultimately included in the systematic review. Analysis of the literature showed various limitations in the scientific information due to the absence of a standardized protocol to evaluate efficacy of hand products, and variation in experimental conditions applied in different studies. However, despite the existence of conflicting results, scientific evidence seems to support the historical scepticism about the use of water-less hand sanitizers in food preparation settings. Water and soap appear to achieve greater removal of soil and microorganisms than water-less products from hands. Alcoholbased products achieve rapid and effective inactivation of various bacteria, but their efficacy is generally lower against non-enveloped viruses. The presence of food debris significantly affects inactivation rates of hand sanitizers. 
52 Foodborne disease via consumption of contaminated food and beverages is 53 considered one of the most common causes of human disease all around the world 54 (45). Norovirus, non-typhoidal Salmonella spp. Listeria monocytogenes, Clostridium 55 perfringens, Campylobacter spp. and Toxoplasma gondii are the foodborne 56 pathogens most commonly reported in the USA, causing 9.4 million episodes of 57 foodborne illness, 55,961 hospitalizations and 1,351 deaths (53). In the UK, the Food 58 Standards Agency estimates there are more than 500,000 food poisoning cases each year, caused by Campylobacter spp. which is responsible for about 280,000 cases each year, followed by Clostridium perfringens with about 80,000 cases,

61 Norovirus with about 74,000 cases and Salmonella which is responsible for the 62 highest number of hospitalizations, about 2,500 each year (27). More than 320,000 63 cases of foodborne zoonotic disease are annually reported in the European Union. 64 The most common microorganisms causing foodborne diseases in this region are 65 Campylobacter spp., Salmonella spp. and viruses such as hepatitis A virus and norovirus (17). Among 31 different microorganisms causing foodborne diseases, five

67 foodborne pathogens, known as the "Top 5", have been identified by food safety experts as highly infective agents that can easily be transmitted by infected food 69 handlers and cause severe illness. The top five foodborne pathogens include: 70 Norovirus, Salmonella Typhi (typhoid-like fever), Escherichia coli O157:H7 or other 71 Enterohaemorrhagic and Shiga toxin-producing E. coli, Shigella spp., and Hepatitis A 72 virus (25). Greig et al. (2007) reviewed a total of 816 reports of foodborne outbreaks 73 from United States, Canada, Europe, Australia and identified 14 agents responsible 74 for most of outbreaks where food workers were implicated. The 14 main agents 75 were Norovirus (or probable Norovirus), Salmonella enterica, Hepatitis A virus, 
Staphylococcus aureus, Shigella spp., Streptococcus Lancefield A and G and parasites like Cyclospora, Giardia and Cryptosporidium (30).

The origins of pathogenic microorganisms in food include the food itself or its source, such as the growing, harvesting or processing environment, as well as cross-contamination and infected food handlers. In industrialized countries infected

food handlers have been identified as an important cause of foodborne illness $(4,31$, 33). Estimates suggest that up to one third of outbreaks in Ireland (4) and $12 \%$ of outbreaks in the United Kingdom (19) are caused by infected employees. Another study of foodborne illness outbreaks in restaurants in the United States identified food handling by infected workers as the main factor contributing to around twothirds $(65 \%)$ of foodborne illness outbreaks (33). Food service facilities including restaurants and catered events are the settings where most food worker associatedoutbreaks occur (56), and contact with bare hands and failure to properly wash hands were the most frequently reported factors contributing to outbreaks (57). In light of this, good personal hygiene and safe food handling practices are essential for preventing foodborne illness.

Hand washing for hand hygiene is the most important practice to prevent the spread of pathogens (6). Hand washing with water and soap is generally considered to be the gold standard method to remove dirt and transient microorganisms from hands. Plain soaps have minimal or no antimicrobial activity against bacteria and viruses, but by surfactant action, friction and final rinsing under water can effectively remove dirt, soil and microbial load from the outer layer of hand skin $(39,60)$. Over the past two decades, increasing interest has been placed on the use of hand cleansing products possessing antimicrobial activity, like antimicrobial soaps, or instant hand sanitizers including both alcohol-based and alcohol-free preparations. 
Antimicrobial soaps are preparations containing both a detergent and antiseptics or disinfectants with antibacterial activity, such as Triclosan, Chlorhexidine gluconate $(\mathrm{CHG})$ or Para-chloro-meta-xylenol (PCMX). Antimicrobial soaps are considered to be effective against Gram positive microorganisms, to have moderate activity against viruses and tubercle bacilli, but to be less effective against Gram negative microorganisms $(34,39)$.

107 Alcohol-based hand sanitizers, or alcohol-based hand rubs (ABHRs), are instant 108 hand hygiene products; the antimicrobial activity of which is due to the ability of alcohol to denature protein. These products usually contain a quantity of alcohol, varying from $60 \%$ to $95 \%$, and a thickening agent or humectants such as polyacrylic acid, glycerin, or propylene glycol to decrease the drying effect of alcohol. ABHRs have documented microbiological activity against bacteria $(21,51)$, fungi and some enveloped viruses including HIV, herpes, adenovirus, influenza and parainfluenza 114 viruses (20). Lower efficacy against non-enveloped "naked" viruses is generally reported in the literature, and the level of inactivation seems to vary a lot depending on the viruses tested, type of alcohol, concentration, and time of exposure $(12,20$, $21,29,32,49,50,52)$. prepared with benzalkonium chloride (BZK) have demonstrated many advantages over ABHRs including residual antimicrobial activity after use, less drying effect on hand skin, and lack of decrease in efficacy after repeated use (13). 
125 Use of water-less hand sanitizers as an alternative to conventional hand washing 126 has long been debated. Despite some potential advantages over conventional water 127 and soap (quicker and easier usage), instant hand products are generally considered 128 to more effectively meet needs in hospital and health-care, rather than food 129 preparation, settings. ABHRs containing $60 \%$ to $95 \%$ alcohol are recommended as 130 an alternative to hand washing in hospital and health-care settings when hands are 131 not visibly soiled (5). In contrast, their use in food establishments has historically been refused because of their inability to remove fat and food debris from soiled hands (23). To date, little research has been conducted to examine the efficacy of hand disinfectants against transient microorganisms normally occurring on food pathogens in food preparation settings. examine the performance of different hand hygiene products against foodborne

\section{MATERIALS AND METHODS}

An extensive literature review was conducted in November 2014 using the electronic databases Web of Science, Scopus and PubMed. The search was limited to articles published in English from 1990 to 2014. Search terms used were: "efficacy of hand washing", "efficacy of hand sanitizers", "evaluation of hand sanitisers", and "effect of hand hygiene products".

Three preliminary criteria were adopted to select journal papers. Only articles that described levels of inactivation of foodborne pathogens (the actual pathogens not surrogate microorganisms), used a research approach with quantitative outcomes, and described studies undertaken in industrialized countries, were included in this study. In contrast, all book chapters, studies carried out on microorganisms not 
150 involved in foodborne illness, studies involving inactivation of foodborne

151 microorganisms from raw food or food contact surfaces were excluded before 152 analysis, based on the title and abstract.

153 Once preliminary results matching search terms were obtained, data extraction 154 was carried out in three steps. Firstly, duplicate articles were identified and removed. 155 Secondly, remaining titles and abstracts were screened for eligibility against 156 inclusion criteria. Thirdly, full text articles were retrieved and assessed in terms of 157 their study design and scientific approach. All articles identified were then critically 158 reviewed by the authors and included as appropriate to provide an overview of the 159 topic.

\section{RESULTS}

From amongst 2108 records originally matching the search terms, 38 unique 163 journal abstracts were preliminarily screened for eligibility after duplicates were removed. Subsequent analysis of full text journal articles permitted selection of the 28 journal articles that are included in this review (Table 1). Among the selected studies testing hand washing products against foodborne pathogens, ten papers provided information on Norovirus, three on Hepatitis A virus, two on Listeria monocytogenes, fourteen on Escherichia coli, eight on Staphylococcus aureus and one on Salmonella spp. No scientific information was found for other pathogenic bacteria like Campylobacter spp. and Bacillus cereus.

171 Besides the use of conventional water and soap or water only, products more 172 generally tested against pathogenic bacteria and viruses included antibacterial liquid 173 soaps, alcohol-based hand sanitizers and non-alcohol based sanitizers including 174 triclosan-, chlorexidine gluconate- $(\mathrm{CHG})$, povidone-iodine- and quaternary 
175 ammonium-based products like benzalkonium chloride (BZK) or benzethonium 176 chloride (BZT), 5-pyrrolidone-2-carboxylic acid (PCA) and copper sulphate 177 pentahydrate (CS). Hand washing practices considered also included use of soap 178 and nailbrush (40), Wash-sanitise, consisting of using hand sanitizers after hand 179 washing with water and soap $(15,30,47)$, and a new hand hygiene regime known as 180 SaniTwice (a registered trademark of James Mann, Handwashing for Life, 181 Libertyville, IL) consisting of a two stage hand cleansing including application of an 182 and a final application of alcohol-based sanitizer (14).

The relative efficacy of products was generally tested in vitro, ex vivo and/or in vivo. Most of the in vitro studies involved experiments carried out using a suspension assay consisting of a standardized quantity of the target microorganism treated with increasing concentrations of the test product, with the aim of estimating the inactivation rate for each product used $(1,10,16,20,21,28,29,54,46,55)$. One in vitro study evaluated inactivation rates of tested products on latex gloves immersed in a solution of phosphate buffered saline (PBS) or crab cooking water artificially contaminated with $5 \log _{10}$ CFU L. monocytogenes/ml (44). Ex vivo tests included experiments carried out on pig skin from a freshly killed pig (the pig skin method) previously treated with sanitizing products, then artificially contaminated with challenge microorganisms to test residual activity of tested products after use $(9,28$, 35, 54). In vivo studies involved experiments carried out with selected human volunteers to estimate the efficacy of each tested product to remove or inactivate target microorganisms from artificially contaminated whole hands, finger pads or gloves. The vast majority of in vivo studies retrieved in the literature were carried out on hands or finger pads artificially contaminated with pure cultures of bacteria or 
200 viruses without the presence of food components or organic material $(9,16,22,29$, $20137,38,41,42,43,47,55)$. Seven studies evaluated the efficacy of hand washing 202 products in a food preparation setting on naturally and artificially soiled hands or 203 gloves $(7,8,14,15,40,44,48)$. Three studies evaluated inactivation rates of 204 products on hands contaminated with viral suspensions prepared with other organic 205 loads like fetal bovine serum or feces $(15,36,40)$. Other factors pertaining to food 206 preparation settings like hygiene of nails (40) and wearing rings when handling food 207 have also been minimally considered (61). A summary of the experimental conditions applied and main findings from in vitro, ex vivo and in vivo evaluations in all studies included in this review are summarized in Table 2. Information relating to specific pathogens will now be summarised.

Norovirus. Because human norovirus (HuNoV) cannot be routinely cultured in vitro, determining the effectiveness of sanitizers and disinfectants against HuNoV is difficult. Methodologies used to estimate level of virus reduction include the use of reverse transcription-quantitative real time PCR to quantify the number of RNA copies of HuNoV extracted and purified from tested samples $(41,42,46)$ and the use of cultivable surrogates like Feline Calicivirus (FCV) and Murine Norovirus (MNV). Norovirus surrogates were generally tested alone as an alternative to $\operatorname{HuNoV}(9,15$, $29,36,38,40,55)$, or in parallel with HuNoV (46).

Liu et al. (41) compared the efficacy of an antibacterial soap, alcohol-based sanitizer containing $62 \%$ ethyl alcohol, and water rinsing for the removal of HuNoV from artificially contaminated finger pads. Ethanol-based hand sanitizer was the least effective hand product tested $\left(0.34 \pm 0.22 \log _{10}\right.$ reduction). The greatest $\log _{10}$ reduction was observed for water rinse only $\left(1.38 \pm 0.49 \log _{10}\right)$ and antibacterial soap $\left(1.1 \pm 0.49 \log _{10}\right)$. A separate study by Liu et al. (42) tested various commercially 
225 available hand hygiene products containing $62 \%$ to $95 \%$ alcohol on finger pads against multiple HuNoV strains. The study showed a wide range of efficacy $(0.10$ to $3.74 \log _{10}$ reduction), varying according to different products and strains tested. The highest level of RNA reduction was achieved by a $70 \%$ ethanol gel containing additional ingredients that seem to potentiate the virucidal activity of alcohol alone. A limitation of the study reported by the authors was the presence of PCR inhibitors in the test products that may have affected PCR amplification and led to an overestimate of virus reduction.

233 Eight papers evaluated the efficacy of hand sanitizers against FCV and MNV. 234 Experimental methods used to estimate viral inactivation included a virus-specific cytopathic effect (CPE) test consisting of culturing post treatment samples on a serial dilution of permissive host cells $(9,15,29,36,38,40,55)$, and a plaque assay test in parallel with TaqMan real-time reverse transcription PCR (46). Park et al. (46) evaluated in vitro virucidal efficacy of seven hand sanitizers containing ethanol, triclosan and chlorhexidine against both Norovirus surrogates (i.e. FCV and MNV) and human norovirus (HuNoV). None of the products demonstrated significant RNA reduction when tested against HuNoV, whereas results achieved for Norovirus surrogates showed different levels of viral reduction measured by plaques assay and RT-qPCR. A general lack of correlation between the two detection methods and different degrees of viral inactivation of FCV or MNV were generally observed. Only a $72 \%$ alcohol $\mathrm{pH} 2.9 \mathrm{ABHR}$ reduced the infectivity of both FCV and MNV (3.4 and $2.6 \log _{10}$, respectively) by the plaque assay test, whereasno correlation was found between reduced infectivity and RNA reduction measured by real-time reverse transcription PCR.. Conflicting results were also reported in two studies evaluating both in vitro and in vivo efficacy of hand products against FCV and MNV. Gehrke et 
al. (29) tested three types of alcohol - ethanol, 1- propanol and 2-propanol. In vitro experiments showed higher effectiveness achieved by 50\% and 70\% 1-propanol (10 ${ }^{4}$-fold reduction) over ethanol and 2-propanol. In contrast, $70 \%$ ethanol achieved higher viral inactivation (3.78 $\log _{10}$ reduction) in vivo than either 1-propanol or 2propanol (3.58 and $2.15 \log _{10}$ reduction, respectively). Steinmann et al. (55) compared virucidal activity of three ABHRs and three antimicrobial soaps. Results from suspension tests demonstrated $\geq 5 \log _{10}$ reduction of both FCV and MNV achieved by two of three ABHRs tested which was greater efficacy than soaps tested (typically $\leq 3 \log _{10}$ reduction). Conversely, the modified finger pad test carried out against MNV only, showed superior antimicrobial activity of a povidone-iodine soap (4.62 $\log _{10}$ reduction) compared to the other ABHRs and soaps tested. Two studies evaluated in vivo efficacy of hand hygiene products against FCV only. Lages et al. (38) tested four ABHRs, three non-alcoholic sanitizers and two triclosancontaining antimicrobial liquid soaps after $30 \mathrm{~s}$ and 2 min exposure times. Limited efficacy of all the products tested was generally observed; only one antimicrobial soap containing $10 \%$ povidone-iodine ( $\leq 2.67 \log _{10}$ reduction) and one ABHR containing $95 \%$ ethanol ( $\leq 1.30 \log _{10}$ reduction) achieved appreciable viral reduction compared to water rinse tested in parallel. Czerwinski and Cozean (9) compared a novel hand sanitizer containing benzethonium chloride (BZK), a $62 \% A B H R$, an antibacterial liquid soap, and water rinse. Apart from a promising level of inactivation shown by the novel hand sanitizer ( $3.49 \log _{10}$ reduction), generally viral reductions were $<1 \log _{10}$ in all the other cases. Two studies evaluated efficacy of products on hands artificially contaminated with a fecal suspension of FCV. Kampf et al. (36) tested efficacy of three ABHRs; greatest reduction in FCV was achieved by a $95 \%$ alcohol containing hand sanitizer $\left(2.17 \pm 1.06 \log _{10}\right)$. Lower concentrations of alcohol 
275 did not demonstrate more than $1 \log _{10}$ viral reduction. Lin et al. (40) compared six 276 hand washing practices on contaminated natural and artificial nails. Use of soap and 277 nail brush $\left(2.54 \pm 0.57 \log _{10}\right.$ reduction) achieved the highest $\log _{10}$ viral reduction, 278 followed by hand washing with antibacterial soap (2.26 $\pm 0.42 \log _{10}$ reduction), and 279 then combined use of soap and hand sanitizer (2.13 $0.93 \log _{10}$ reduction). In 280 contrast, the use of hand sanitizer alone demonstrated limited efficacy $\left(0.86 \pm 55 \log _{10}\right.$ 281 reduction). Presence of long nails on treated hands was found to significantly impact 282 efficacy of all the hand products tested. Finally, one study carried out by Edmonds et 283 al. (15) compared four hand hygiene regimes on hands contaminated with a viral suspension of MNV prepared with $0.5 \%$ fetal bovine serum to mimic soiling with organic matter. Hand hygiene practices included an antimicrobial soap, a $70 \%$ alcohol gel, hand washing followed by hand sanitizing, and SaniTwice. Sanitizing with $70 \%$ alcohol gel was slightly more effective $\left(2.6 \pm 0.41 \log _{10}\right.$ reduction) than hand washing with antimicrobial soap $\left(1.79 \pm 0.29 \log _{10}\right.$ reduction). A higher level of viral reduction was achieved by SaniTwice $\left(4.04 \pm 0.33 \log _{10}\right)$ and by the combination of conventional hand washing and sanitizing $\left(3.19 \pm 0.31 \log _{10}\right)$.

Hepatitis A virus (HAV). Little information is available in the scientific literature about relative effectiveness of hand washing products against HAV. Only three studies describing efficacy of hand washing products against HAV were retrieved $(20,21,43)$. Fendler et al. (21) and Fendler \& Groziak (20) demonstrated limited in vitro efficacy of a commercially available alcohol-based hand sanitizer containing $62 \%$ alcohol and emollients against HAV. The levels of inactivation achieved by $30 \mathrm{~s}$ timed exposure were 1.75 and $1.25 \log _{10}$ reduction, respectively, corresponding to $94.37 \%(21)$ and $94.4 \%$ (20) reduction of original inoculum. 
A study by Mbithi et al. (43) evaluated elimination rates of 10 different products on whole hands or finger pads artificially contaminated with a mixture of viruses and feces. Formulations tested included a non-medicated soap, five ethanol-based hand sanitizers, and four antibacterial liquid soaps, compared to tap water without soap used as a control. None of the tested products reached a level of inactivation of $99.9 \%$, which is generally desired. Inactivation rates observed from both whole-hand and finger pad methods ranged from $79 \%$ to $94 \%$. One antibacterial soap and nonmedicated soap attained a higher level of virus reduction $(\leq 94.56 \pm 5.75 \%$ and $\leq 91.39 \pm 2.65 \%$, respectively) than alcohol based hand sanitizers $(\leq 90.67 \pm 2.08 \%)$ and tap water $(\leq 81.57 \pm 4.5 \%)$. Residual infectivity, estimated as a mean number of Plaque Forming Units through a plaque assay test, ranged from 0 to 0.64 PFU for ABHRs, 0.63 to 1.74 PFU for antimicrobial soaps, 1.57 PFU for plain soap and 3.88 PFU for tap water. No information was found in the literature about the efficacy of hand washing and hand sanitizers against HAV on hands soiled with food components.

Listeria monocytogenes. Only two papers describing in vitro and in vivo efficacy of sanitizing products against $L$. monocytogenes were found in the literature $(21,44)$. Fendler et al. (21) reported $>5 \log _{10}$ reduction of $L$. monocytogenes achieved in vitro by a commercially available hand sanitizer containing $62 \%$ alcohol on a $30 \mathrm{~s}$ timed exposure kill test. McCarthy (44) compared the in vivo efficacy of one hand sanitizer and five disinfectants, including two chloride-based, one iodine-based, one peroxidebased, one quaternary ammonium-based sanitizer, on contaminated latex gloves. The impact of the organic compounds on inactivation rates of the tested products was estimated through immersion of gloves in both sterile phosphate buffered saline (PBS) and crab cooking water artificially contaminated with $5 \log _{10} \mathrm{CFU} / \mathrm{ml}$ of $L$. 
monocytogenes. Of the different products tested, only the peroxide-based product achieved $5 \log _{10}$ reduction of attached L. monocytogenes on both soiled and nonsoiled contaminated gloves. The two chloride-based and the quaternary ammoniumbased products achieved $5 \log _{10}$ reduction on gloves contaminated with PBS suspensions of $L$. monocytogenes (i.e. no food residue present) but demonstrated lower efficacy ( $\leq 1-2 \log _{10}$ reduction) in the presence of crab cooking water. lodinebased sanitizer and alcohol-based instant hand sanitizer demonstrated lower efficacy in both cases. No data about the efficacy of conventional hand washing in removing $L$. monocytogenes from gloves or hands was found in the literature.

Staphylococcus aureus and Escherichia coli. Six studies assessed in vitro and/or ex vivo efficacy of hand sanitizers against St. aureus and E. coli. Hand formulations included conventional ABHRs and new generation hand products containing a combination of active antimicrobials and other compounds like thickening agents, emollients and natural compounds. Fendler et al. (21) reported that $>5 \log _{10}$ reduction was achieved by a $62 \%$ alcohol based sanitizer against both methicillin-resistant and vancomycin-tolerant and methicillin-resistant St. aureus, non-pathogenic E. coli and E. coli $\mathrm{O} 157: \mathrm{H} 7$. High in-vitro inactivation rates were also reported by Biagi et al. (1), Czerwinski et al. (10), Gaonkar et al. (28), Kaiser et al. (35), and Shintre et al. (54). Biagi et al. (1) tested the in vitro efficacy of a new combination of two natural compounds, pyrrolidone-2-carboxylic acid (PCA) and copper sulphate pentahydrate (CS). The combination of PCA and CS demonstrated higher efficacy than $70 \%$ ethanol and $60 \%$ isopropanol used alone. Czerwinski et al. (10) tested the efficacy of a novel alcohol-based antiseptic and a novel water-based antiseptic lotion prepared with a synergistic combination of ingredients centred on Benzethonium chloride (BZT). The novel water-based product demonstrated 
349 equivalent antimicrobial $(99.9 \%)$ activity against $E$. coli and St. aureus strains 350 compared to the other alcohol-based product. Gaonkar et al. (28) tested an ABHR 351 prepared with an emollient (Octoxy) and other additional ingredients against E. coli 352 and methicillin-resistant St. aureus. In vitro evaluations showed $>7 \log _{10}$ reduction of 353 both E. coli and St. aureus and ex vivo tests showed higher antimicrobial activity and 354 superior residual activity after use of the novel Octoxy compared to the two other 355 ABHRs applied in parallel as a control. Kaiser et al. (35) compared ex vivo a 356 combination of a surgical scrub containing $4 \%$ Chlorexidine gluconate (CHG) and 357 ABHRs prepared with and without thickening agents against St. aureus. Hand

sanitizers thickened with anionic polymers were found to negatively impact persistent activity of $\mathrm{CHG}$. In contrast, no negative effect was observed for $\mathrm{ABHRs}$ alone or thickened with non-ionic compounds. Shintre et al. (54) tested the synergistic effect of alcohol and quaternary ammonia in combination with moisturizers or essential oils in vitro and ex vivo. Synergistic combination of farnesol and BZT demonstrated better prolonged activity (i.e. $20-35$ min post application) against St. aureus and E. coli than other hand sanitizers and chemicals compounds used alone.

The high level of bacterial inactivation generally observed in vitro does not necessarily reflect the actual capacity of products to remove transient microorganisms from the outer layers of skin of hands. Incomplete effectiveness against target microorganisms from cleaned hands is generally reported in all studies carried out on hands artificially contaminated with E. coli. Edmonds et al. (16) compared the efficacy of two novel $70 \%$ alcohol gel and foam, seven commercially available ABHRs, and two World Health Organization recommended formulations containing 60-90\% alcohol against one methicillin-resistant St. aureus strain. Results showed superior efficacy of the novel gel and foam preparations after single and 
374 multiple uses compared to the other products. However none of the products 375 exceeded $3 \log _{10}$ reduction of the target microorganism. Fishler et al. (22) evaluated 376 the effectiveness of two hand washing regimes in reducing transient bacteria after 377 single wash and subsequent potential transfer of bacteria to a ready-to-eat food. The 378 antimicrobial soap achieved a higher level of bacterial removal (>3 $\log _{10}$ reduction) 379 than plain soap ( $\leq 2 \log _{10}$ reduction), but failed to avoid the transfer of seeded 380 bacteria to a ready-to eat food item. Kampf et al. (37) reported limited efficacy of two 381 ABHRs on hands artificially contaminated with E.coli. Bacterial inactivation achieved 382 by two $62 \%$ alcohol containing products was only slightly better $(\leq 3.5 \pm 0.45$ and

$3.58 \pm 0.71 \log _{10}$ reduction) than rubbing under running water applied in parallel (2.39 \pm 0.57$)$. Paulson et al. (47) examined the abilities of four hand washing regimes including plain soap, an antimicrobial soap, an alcohol hand sanitizer, and combined use of an antimicrobial soap and a ABHR (used after hand washing). All the products used alone performed equally and none exceeded $2 \log _{10}$ reduction. Higher efficacy (3.28 $\log _{10}$ reduction) was observed by combined use of hand washing and hand sanitizing.

Salmonella spp. Little information about the efficacy of sanitizing products against Salmonella spp. is available in the literature. Only one in vitro study (21) reporting $>5 \log _{10}$ reduction of Salmonella Enteritidis and Salmonella Typhimurium being achieved by a $62 \%$ ABHR was retrieved.

\section{Efficacy of hand products on hands soiled with food components.} Experimental conditions described in the literature to mimic food preparation settings include contamination of food workers hands with natural soil encountered in the food service industry (7), or hands artificially inoculated with pure cultures of bacteria mixed with crab cooking water (44), chicken or beef broth $(14,15,40)$, ground beef 
$399(7,14,15,40)$, dirt or cooking oil (48). Efficacy of hand products was estimated based on the enumeration of microorganisms released from treated hands, or based on the enumeration of bacteria remaining on hands. Methods for enumerating released bacteria included the glove juice $(14,15,61)$ or the hand rinse $(8,48)$ techniques. Both techniques consist of enumerating bacteria released from washed hands previously placed into a glove or a bag filled with sterile water or buffer. Conversely, enumeration of bacteria remaining on the hands after hand washing or hand sanitizing is usually estimated through image analysis or by pressing washed hand palms onto the surface of an agar plate (7).

Four studies compared efficacy of hand hygiene products on soiled hands. Courtenay et al. (8) compared eliminating abilities of three hand washing regimes 410 including rinsing with warm water, rinsing with cold water and hand washing with 411 water and soap on hand and gloves contaminated with E. coli and ground beef. 412 Water and soap achieved a higher level of removal than other hand hygiene 413 regimes, but the level of bacterial removal was higher from hands (99.98\%) than 414 from gloves (99.13\%). The efficacy of four hand sanitizers containing $62 \%$ ethanol was also compared on clean hands contaminated with $10^{6} \log _{10}$ cfu of $E$. coli/ml of broth. The level of bacterial reduction achieved by the four hand sanitizers ranged 417 from $96.44-90.40 \%$ and was consistently lower than that observed for water and 418 soap. Charbonneau et al. (7) tested eliminating abilities of a plain soap, a $70 \%$ alcohol hand sanitizer, and combined use of hand washing and $\mathrm{ABHS}$ on hands naturally contaminated with raw chicken and ground beef. The study showed higher efficacy achieved by plain soap over the other hand hygiene regimes. Limited

422 efficacy of ABHRs on clean hands or hands soiled with dirt and oil was also reported 423 in a study by Pickering et al. (48). Bacterial reduction achieved did not exceed $2 \log _{10}$ 
424 of seeded E.coli $\left(10^{7} \mathrm{CFU} / \mathrm{ml}\right)$ in all cases. Efficacy of hand hygiene practices in 425 moderately and heavily soiled conditions has been evaluated in two studies $(14,15)$.

426 Edmonds et al. (15) demonstrated superior efficacy of combined use of water and 427 soap and hand sanitizing than water and soap or antimicrobial soap used alone.

428 Reported levels of bacterial inactivation achieved from both moderately and heavily 429 soiled hands were $>5.0$ and $>4.6 \log _{10}$ reduction, respectively. Edmonds et al. (14) 430 tested eliminating capacity of SaniTwice carried out with three $62 \%$ to $70 \%$ alcohol 431 products compared to a plain soap, an antibacterial soap and a $70 \%$ alcohol gel 432 used alone. SaniTwice with $70 \%$ alcohol foam showed higher efficacy than water and soap and other alcohol-based regimes. The level of bacterial reduction observed on moderately and heavily soiled hands was 4.61 and $3.92 \log _{10}$, respectively. Heavy soil condition was found to impact efficacy of all the practices tested $\left(<1-2 \log _{10}\right.$ reduction). evaluated the efficacy of hand washing techniques in the removal of bacteria or viruses from natural and artificial nails (40) or from hands with rings present (61). Wongworawat et al. (61) compared the efficacy of three hand sanitizers, including a povidone-iodine, a water-aid alcohol and an alcohol-chlorhexidine hand sanitizer, on hands with and without rings. The alcohol-chlorhexidine hand sanitizer showed slightly higher efficacy than other products. No significant difference in the number of bacteria retrieved from cleansed hands with and without rings was generally observed. Results reported suggest that the presence of rings should not significantly impact effectiveness of hand sanitizers.

Lin et al. (40) assessed effectiveness of different cleansing products and hand 448 practices from natural and artificial nails on hands inoculated with $E$. coli or FCV. 
449 Use of a nailbrush and soap achieved the highest removal of target microorganisms.

450 However the presence of long nails significantly impacted efficacy of all regimes

451 tested, suggesting that maintaining short fingernails is essential to reduce the risk of

452 transmitting hazardous microorganisms when handling food.

microorganisms from spreading from people's hands to food. Contact with bare hands and failure to properly wash hands have been reported as the main risk factor contributing to foodborne disease caused by food handlers (57). European Union

472 on the hands of food handlers is a mixture of Enterobacteriaceae and other 473 mesophilic bacteria in the presence of fat and other soil (11). Various pathogens with 
474 very low infective doses (1 to 100 units) including viruses, parasites and enteric 475 bacteria can be present on contaminated hands in high numbers (58). Pathogens 476 carried by contaminated hands can be easily transferred to food and hand contact 477 surfaces and can survive for long periods $(58,59)$. The ideal hand hygiene regime to 478 be used in a food setting should ensure maximum removal of food components and 479 food flora from cleaned hands in order to minimize the level of transferable 480 microorganisms. Most of the hand disinfectants, including medicated soaps and 481 instant hand sanitizers, have a broader antimicrobial activity than plain soaps but are 482 generally considered not to properly meet the needs of food workers because they are unable to remove food soil from cleansed hands (23).

484 This systematic review evaluated the scientific information available in the 485 literature about the efficacy of conventional and improved hand hygiene products in 486 relation to their use in food preparation settings. Analysis of the literature showed the existence of conflicting reports about the efficacy of soaps and hand sanitizers against foodborne pathogens. No standardized method to estimate removal and inactivation rates of target pathogens seems to be available and the varying experimental conditions (including quantity of product used, duration of treatment, type of food soil used) between different studies makes comparison of results 492 difficult. Hand washing with water and soap is generally reported to achieve 493 effective removal of bacteria and soil from hands $(7,8,14,15)$ and gloves $(8)$ and to be superior to other products in the removal of bacteria and viruses from fingernails when used with a nailbrush (40). However, a residual level of microorganisms even after proper washing is generally reported $(7,8,14,15,40)$, suggesting that hand washing alone cannot ensure elimination of risk in relation to bacterial transmission 498 from hands to food. Conventional hand washing is more effective on contaminated 
hands than on gloves (8) suggesting that frequent changes of gloves rather than washing gloves when they become visibly soiled would more effectively minimize risk of bacterial contamination between different food preparation steps.

Information on the efficacy of antimicrobial soaps over conventional plain soaps is also controversial and the existence of conflicting results has been previously reported in two other reviews $(31,60)$. Apart from one study reporting lower efficacy compared to plain soap (47), the evidence seems to indicate that antimicrobial or medicated soaps can achieve a slightly higher level of microbial inactivation on artificially contaminated hands without food residue present $(22,43)$, whereas their efficacy on soiled hands is similar to conventional soaps $(15,40)$.

Instant hand sanitizers have shown high and rapid in vitro efficacy against various target bacteria $(10,16,21,54)$, whereas their efficacy against naked viruses seems to be lower $(20,21,38,46)$ and vary according to different viruses tested, type of alcohol and concentration used $(29,46,55)$. These findings are in general agreement with four other reviews $(2,3,31,60)$. Apart from some improved formulations $(9,32)$, instant hand sanitizers used in vivo do not usually exceed 2-3 $\log _{10}$ microbial reduction $(16,37,41,42,47,48)$ and their efficacy seems to be affected by the presence of food debris, as observed on both moderate (44) and heavily soiled hands $(7,14,40)$, as only one study included in this systematic review reported similar rates of bacterial inactivation on both clean and soiled hands (48). Instant hand sanitizers used alone seem not to be a reliable substitute for conventional hand washing in food establishments (7). In contrast, their application after hand washing, previously carried out with either antimicrobial or plain soap (i.e. wash-sanitize regimes), seems to be more effective than hand sanitizer or soaps used alone $(15,47)$; levels of bacterial inactivation have been demonstrated to 
524 significantly increase up to 4 or $5 \log _{10}$ reduction on both moderately and heavily 525 soiled hands (15).

526 Preliminary results reported for SaniTwice are also encouraging (14). The method 527 tested on hands moderately and heavily soiled with a mixture of food components 528 and $E$. coli showed good levels of bacterial reduction ( $4 \log _{10}$ reduction). A similar 529 level of inactivation is also reported against MNV on artificially contaminated hands. 530 These findings suggest that this hand hygiene regime could be used as an 531 alternative to wash-sanitize when water and soap are not available. However, no 532 evidence about the efficacy of this hand hygiene regime against HuNoV or HAV on 533 soiled hands seems to be available in the literature. For this reason, further studies 534 would be needed to prove the effectiveness of SaniTwice in different food settings 535 and against different foodborne pathogens.

536 Finally, a new generation of alcohol-free lotions is attracting more and more 537 interest $(1,28,35)$. Evidence from in vitro and ex vivo studies showed similar 538 efficacy against target bacteria compared to alcohol-based products, with prolonged 539 activity after application, and potentially less skin irritation. However, very little is 540 known about their efficacy against viruses, and no evidence about their inactivation 541 rates on soiled hands seems to be available in the literature currently. ACKNOWLEDGEMENTS

544 This material is based upon works supported by safefood, The Food Safety 545 Promotion. Board, under Grant No. 06-2014 
1. Biagi, M., D. Giachetti, E. Miraldi, and N. Figura, 2014. New non-alcoholic formulation for hand disinfection. J. Chemo. 26(2):86-91.

2. Bloomfield, S.F., A.E. Aiello, B. Cookson, C. O’ Boyle, and E.L. Larson, 2007. The effectiveness of hand hygiene procedures in reducing the risks of infections in home and community settings including hand washing and alcohol-based hand sanitizers. mJ. Infect. Control. 35(10) supplement 1:S27-64

3. Bloomfield, S.F. and EA Scott, 2013. A risk assessment approach to use of antimicrobials in the home to prevent spread of infection. Am. J. Infect. Control. 41: S87-93.

4. Bonner, C., B. Foley, and M. Fitzgerald, 2001. Analysis of outbreaks of infectious intestinal disease in Ireland: 1998 and 1999. Ir. Med. J. 94(5):365-372.

5. Centers for Disease Control and Prevention (CDC), 2002. Guidelines for hand hygiene in health-care settings: recommendation of the Healthcare Infection Control Practices Advisory Committee and the HICPA/SHEA/APIC/IDSA Hand Hygiene Task Force. Morb. Mort. Week. Rep. 51:1-56.

6. Centers for Disease Control and Prevention (CDC), 2009. Vessel Sanitation Program - OPRP - General information on Hand Hygiene. Available at: http://www.cdc.gov/nceh/vsp/cruiselines/hand hygiene general.htm Accessed on 3 February 2016.

7. Charbonneau, D.L., J.M. Ponte, and B.A. Kochanowsky, 2000. A method of assessing the efficacy of hand sanitizers: use of real soil encountered in the food service industry. J. Food Prot. 63(4):495-501. 
8. Courtenay, M., L. Ramirez, B. Cox, I. Han, X. Jiang, and P. Dawson, 2005. Effect of various hand hygiene regimes on removal and/or destruction of Escherichia coli on hands. Food Serv. Technol. 5:77-84.

9. Czerwinski, S.E., and J. Cozean, 2012. An evaluation of a hand sanitiser product to reduce norovirus cross infection. Brit. Global Trav. Health Assoc. 20:42-46.

10. Czerwinski, S.E., J. Cozean, and C. Cozean, 2014. Novel water-based antiseptic lotion demonstrates rapid, broad-spectrum kill compared with alcohol antiseptic. J. Infect. Publ. Health 7(3):199-204.

11.De Wit, J.C., and E.H. Kampelmaker, 1981. Some aspects of microbial contamination of hands of workers in food industries. Zentral. Fur Bakteriol. Mikrobiol. Hyg. 172:290-300.

12. Duizer E, P Bijkerk, B Rockx, A De Groot, F Twisk, and M Koopmans, 2004. Inactivation of caliciviruses. Appl. Environ. Microbiol. 70: 4538-43.

13. Dyier, D.I., K.B. Gernraich, and P.S. Wadhams, 1998. Testing a new alcohol-free hand sanitizer to combat infection. AORN J. 68(2):239-241.

14. Edmonds, S.L., J. Mann, R.R. McCormack, D.R. Macinga, C.M. Fricker, J.M. Arbogast, and M.J. Dolan, 2010. SaniTwice: a novel approach to hand hygiene for reducing bacterial contamination on hands when soap and water are unavailable. J. Food Prot. 73(12):2296-2300.

15.Edmonds, S.L., R.R. McCormack, S.S. Zhou, D.R. Macinga, and C.M. Fricker, 2012. Hand hygiene regimens for the reduction of risk in food service environments. J. Food Prot. 75(7):1303-1309.

16. Edmonds, S.L., D.R. Macinga, P. Mays-Suko, C. Duley, J. Rutter, W.R. Jarvis, and J.W. Arbogast, 2012. Comparative efficacy of commercially available 
alcohol-based rubs and World Health Organization-recommended hand rubs: formulation matters. Amer. J. Infect. Cont. 40:532-525.

17. European Food Safety Authority (EFSA) 2011. EFSA explains foodborne disease: Food-borne zoonosis. ISBN number: 978-92-9199-384-0. Fact sheet available at: http://www.efsa.europa.eu/en/topics/factsheets/factsheetfoodborne zoonoses Assessed on 3 February $2016 .$.

18. European Parliament, 2004. Regulation (EC) No 852/2004 of the European Parliament and of the Council, of 29 April 2004, on the hygiene of foodstuffs. Off. J. Eur. Union L 139/1, 30/4/2004.

19. Evans HS, Madden P, Douglas C, Adak GK, O' Brien SJ, Djuretic T, Wall PG and , Stanwell-Smith R. 1998. General outbreaks of infectious intestinal disease in England and Wales: 1995 and 1996. Comm. Dis Pub. Health 1(3): 165-71.

20. Fendler, E., and P. Groziak, 2002. Efficacy of alcohol-based hand sanitizers against fungi and viruses. Infect. Cont. Hosp. Epidemiol. 3(2):61-62.

21. Fendler, E.J., Y. Ali, B.S. Hammond, M.K. Lyons, M.B. Kelley, and N.A. Vowell, 2002. The impact of alcohol hand sanitizer use on infection rates in an extended care facility. Amer. J. Infect. Cont. (30)4:226-232.

22. Fischler, G.E., J.L. Fuls, E.W. Dail, M.H. Duran, N.D. Rodgers, and A.L. Waggoner, 2007. Effect of hand wash agents on controlling the transmission of pathogenic bacteria from hands to food. J. Food Prot. 70(12):2873-2877.

23. Food and Drug Administration (FDA), 2009. Food Code 2009 Chapter 2 Management and Personnel - 2-301-16 Hand Antiseptics: Available at: http://www.fda.gov/Food/GuidanceRegulation/RetailFoodProtection/FoodCode/u cm181242.htm. Accessed on 3 February 2016. 
619 24. Food and Drug administration (FDA) 2009 Chapter 2 - Management and 620 personnel - Ams and Hands - 2-301-12 Cleaning procedures. Available 621 at:http://www.fda.gov/Food/GuidanceRegulation/RetailFoodProtection/FoodCode 622 /ucm181242.htm

623 25. Food and Drug Administration (FDA), 2014. Foodborne Illness. Available at: 624 http://www.fda.gov/food/guidanceregulation/retailfoodprotection/industryandregul 625 atoryassistanceandtrainingresources/ucm113827.htm\#foodborne illness

$626 \quad$ Accessed on 3 February 2016.

627 26. Food and Drug Administration (FDA), 2014. FDA Fact Sheet on Hand Hygiene in 628 Retail and Food Service Establishments. Available at: 629 http://www.fda.gov/Food/GuidanceRegulation/RetailFoodProtection/Industryand 630 RegulatoryAssistanceandTrainingResources/ucm135577.htm Accessed on 3 $631 \quad$ February 2016.

632 27. Food Standards Agency (FSA) 2014. New UK food poisoning figure published. 633 Available at: https://www.food.gov.uk/news-updates/news/2014/6097/food 634 poisoning Accessed on 3 February 2016.

635 28. Gaonkar, T.A., I. Geraldo, L. Caraos, and S.M. Modack, 2005. Efficacy of hand 636 rubbing containing a synergistic combination of emollient and preservatives; 637 prolonged activity against transient pathogens. J. Hosp. Infect. 59:12-18.

638 29. Gehrke, C., J. Steinmann, and P. Goroncy-Bermes, 2004. Inactivation of Feline 639 Calicivirus, a surrogate of Norovirus (formerly Norwalk-like viruses), by different 640 types of alcohol in vitro and in vivo. J. Hosp. Infect. 56:49-55.

641 30. Greig, J.D., E.C.D. Todd, C.A. Barleson, and B.S. Micheals, 2007. Outbreaks 642 where food workers have been implicated in the spread of foodborne disease. 
Part 1. Description of the problem, methods, and agents involved. J. Food Prot. 70(7): 1752-1761

31. Guzewich, J., and M. Ross, 1999. Evaluation of risks related to microbial contamination of ready to eat food by food preparation workers and the effectiveness of interventions to minimize those risks. White Paper, Section One. A literature review pertaining to foodborne disease outbreaks caused by food workers 1975-1998. Food and Drug Administration, Centre for Food Safety and Applied Nutrition, $1999 . \quad$ September ailable at: http://handwashingforlife.com/files/rte fd prep risk eval.pdf Accessed on 3 February 2015.

32. Hammond B, Y Ali, E Fendler, M Dolan, and S Donovan, 2000. Effect of handsanitizer use on elementary school absenteeism. Amer. J Infect Control. 28: 340-6.

33. Hedberg, C.W., S.J. Smith, E. Kirkland, V. Radke, T.F. Jones, C.A. Selman, and the EHS-Networking group, 2006. Systematic environmental evaluations to identify food safety differences between outbreak and non-outbreak restaurants. J. Food Prot. 69(11):2697-2702.

34. Jones, R.D., H.B. Jampani, L. Jerry, J.L. Newman, and A.S. Lee, 2000. Triclosan: a review of effectiveness and safety in health care setting. Amer. J. Infect. Cont. 28:184-196.

35. Kaiser, N., D. Klein, P. Karanja, Z. Greten, and J. Newman, 2009. Inactivation of chlorhexidine gluconate on skin by incompatible alcohol hand sanitizing gels. Amer. J. Infect. Cont. 37(7):569-573. 
36. Kampf, G., D. Grotheer, and J. Steinmann, 2005. Efficacy of three ethanol-based hand rubs against Feline Calicivirus, a surrogates virus for Norovirus. J. Hosp. Infect. 60:144-149.

37. Kampf, G., S. Marschall, S. Eggerstedt, and C. Ostermeyer, 2010. Efficacy of ethanol-based hand foams using clinically relevant amounts: a cross-over controlled study among healthy volunteers. BMC Infect. Dis. 10:78.

38. Lages, S.L., M.A. Ramakrishnan, and S.M. Goyal, 2008. In-vivo efficacy of hand sanitisers against Feline Calicivirus: a surrogate for Norovirus. J. Hosp. Infect. 68(2):159-163.

39. Larson, E.L., 1995. APIC guidelines for hand washing and hand antisepsis in health care settings. Amer. J. Infect. Cont. 149:2749-2753.

40. Lin, C.M., F.M. Wu, H.K. Kim, M.P. Doyle, B.S. Micheals, and L.K. Williams, 2003. A comparison of hand washing techniques to remove Escherichia coli and Caliciviruses under natural or artificial fingernails. J. Food Prot. 66(12):22962301.

41. Liu, P., Y. Yuen, H.M. Hsiao, L.A. Jaykus, and C. Moe, 2010. Effectiveness of liquid soap and hand sanitizer against Norwalk virus on contaminated hands. Appl. Environ. Microbiol. 76(2):394-399.

42. Liu, P., D.R. Macinga, M.L. Fernandez, C. Zapka, H.M. Hsiao, B. Berger, J.W. Arbogast, and C.L. Moe, 2011. Comparison of the activity of alcohol-based hand rubs against human Norovirus using finger pad method and quantitative realtime PCR. Food Environ. Virol. 3:35-42.

43. Mbithi, J.N., V.S. Springthorpe, S.A. Sattar, 1993. Comparative in vivo effectiveness of hand-washing agents against Hepatitis A virus (HM-175) and Poliovirus type1 (Sabin). Appl. Environ. Microbiol. (59)10:3463-3469. 
44. McCarthy, S.A., 1996. Effect of sanitizers on Listeria monocytogenes attached to latex gloves. J. Food Safety 16:231-237.

45. National Institute of Allergies and Infectious disease (NIAID), 2014. Food borne diseases. Available at: https://www.niaid.nih.gov/topics/foodborne/Pages/default. aspx Accessed on 3 February 2016.

46. Park, G.W., L. Barclay, D. Macinga, D. Charbonneau, C.A. Pettigrew, and J. Vinjé, 2010. Comparative efficacy of seven hand sanitizers against Murine Norovirus, Feline Calicivirus, and GII.4 Norovirus. J. Food Prot. 73(12):22322238.

47. Paulson, D.S., C. Riccardi, C.M. Beausoleil, E.J. Fendler, M.J., Dolan, L.V. Dunkerton, and A.W. Ronald, 1999. Efficacy evaluation of four hand cleansing regimes for food handlers. Dairy Food Environ. Sanit. 19(10), 680-684.

48. Pickering, A.J., J. Davis, and A.B. Boehm, 2011. Efficacy of alcohol-based hand sanitizer on hands soiled with dirt and cooking oil. J. Water Health 9(3):429-433.

49. Rabenau HF, G Kampf, J Cinati, and HW Doerr, 2005. Efficacy of various disinfectants against SARS coronavirus. J. Hosp. Infect. 61:107-11.

50. Rotter, M.L., 1996. Alcohol for antisepsis of hands and skin. In: Ascenzi, J.M., ed., Handbook of Disinfectants and Antiseptics. New York: Marcel Dekker, pp. 177-233.

51. Rotter, M., 1999. Hand washing and hand disinfection. In: Mayhall C.G., ed., Hospital Epidemiology and Infection Control, $2^{\text {nd }}$ edition. Philadelphia: Lippincott Williams \& Wilkins, pp.1339-1355.

52. Sattar, S.A., M. Abehe, A.J. Bueti, H. Jampani, J. Newman, and S. Hua, 2000. Activity of an alcohol-based hand gel against human adeno-, rhino-, and 
rotaviruses using the finger pad method. Infect. Cont. Hosp. Epidemiol. 21:516519.

53. Scallan E, RM Hoekstra, FJ Angulo, RV Tauxe, MA Widdowson, Roy SL, Jones JL, and PM Griffin, 2011. Foodborne illness acquired in the United States major pathogens. Emerg Infec. Dis. 17: 7-17 Available at: http://wwwnc.cdc.gov/eid/article/17/1/P1-1101 article.htm. Accessed on 3 February 2016.

54. Shintre, M.S., T.A. Gaonkar, and S.M. Modak, 2006. Efficacy of an alcoholbased health care hand rub containing synergistic combination of farnesol and benzethonium chloride. Int. J. Hyg. Environ. Health 209:477-487.

55. Steinmann, J., D. Paulmann, B. Becker, B. Bischoff, E. Steinmann, and J. Steinmann, 2012. Comparison of virucidal activity of alcohol-based hand sanitizers versus antimicrobial hand soaps in vitro and in vivo. J. Hosp. Infect. 82:277-280.

56. Todd E.C.D, J.D. Greig, C.A. Barleson, and B.S. Micheals, 2007. Outbreaks where food workers have been implicated in the spread of foodborne disease. Part 2. Description of outbreaks by size, severity, and setting. J. Food Prot. 70(8): 1975-1993.

57. Todd E.C.D, J.D. Greig, C.A. Barleson, and B.S. Micheals, 2007. Outbreaks where food workers have been implicated in the spread of foodborne disease. Part 3. Factors contributing to outbreaks and description of outbreaks. J. Food Prot. 70(9): 2199-2217.

58. Todd E.C.D, J.D. Greig, C.A. Barleson, and B.S. Micheals, 2008. Outbreaks where food workers have been implicated in the spread of foodborne disease. Part 4.Infective dose and pathogen carriage. J. Food Prot. 70(11): 2339-2373. 
740 59. Todd E.C.D, J.D. Greig, C.A. Barleson, and B.S. Micheals, 2009. Outbreaks 741 where food workers have been implicated in the spread of foodborne disease. 742 Part 6. Transmission of pathogens in food processing and preparation 743 environment. J. Food Prot. 70(1): 202-219.

744 60. World Health Organization, 2009. WHO guidelines on hand hygiene and health745 care. First global patient safety challenge clean care is safer care. Section 11.2 : 746 Plain (non-antimicrobial soap). Geneva, World Health Organization; 2009. ISBN$747 \quad$ 13: $978-92-4-159790-6$.

748 61. Wongworawat, M.D., G. Sidney, and M.D. Jones, 2007. Influence of rings on the 749 efficacy of hand sanitization and residual bacterial contamination. Infect. Cont. $750 \quad$ Hosp. Epidemiol. 28(3): 351-353.

751

752

753

754 
755 Table 1. Number of scientific publications matching search terms retrieved from

756 three different electronic databases.

\begin{tabular}{lcccc}
\hline Search term & $\begin{array}{c}\text { Web of } \\
\text { Science }\end{array}$ & Scopus & PubMed & Total \\
\hline "Efficacy of hand washing" & 351 & 690 & 456 & 1497 \\
"Efficacy of hand sanitizers" & 63 & 62 & 23 & 148 \\
"Evaluation of hand sanitisers" & 28 & 30 & 2 & 60 \\
"Effect of hand hygiene products" & 166 & 160 & 77 & 38 \\
\hline Number of unique articles & 21 & 10 & 7 & 28 \\
retrieved & 4 & 4 & 5 & \\
\hline Number of articles excluded* & 17 & 6 & \\
\hline Number of articles reviewed & & & \\
\hline
\end{tabular}




\section{Table 2. Summary of results regarding efficacy of hand sanitisers presented in the scientific papers included in this systematic}

\section{6 review.}

\begin{tabular}{|c|c|c|c|c|}
\hline References & Microorganism & Test method & Hand hygiene products and disinfectants & Reduction observed \\
\hline \multirow{11}{*}{$\begin{array}{l}\text { Czerwinski \& Cozean } \\
\text { (9) }\end{array}$} & FCV & Finger pad & Novel alcohol-based antiseptic containing BZT & $3.49 \log _{10}$ \\
\hline & & & Hand sanitizer ( $62 \%$ ethanol) & $0.14 \log _{10}$ \\
\hline & & & Hand washing with antibacterial soap & $0.67 \log _{10}$ \\
\hline & & & Water rinse & $1.09 \log _{10}$ \\
\hline & & Pig skin method & Novel alcohol-based antiseptic containing BZT & \\
\hline & E. coli & 2 min post application & & $1.65 \log _{10}$ \\
\hline & & 1h post application & & $1.34 \log _{10}$ \\
\hline & & 4h post application & & $1.15 \log _{10}$ \\
\hline & St. aureus & 2 min post application & Novel alcohol-based antiseptic containing BZT & $1.87 \log _{10}$ \\
\hline & & 1h post application & & $2.14 \log _{10}$ \\
\hline & & 4h post application & & $1.62 \log _{10}$ \\
\hline \multirow[t]{14}{*}{ Edmonds et al. (15) } & & Moderate food soil load & Non-antimicrobial hand wash & $3.10 \pm 0.61 \log _{10}$ \\
\hline & & & PCMX hand wash & $3.56 \pm 0.64 \log _{10}$ \\
\hline & & & WS (non-antimicrobial hand wash + 62\% EtOH foam) & $3.81 \pm 0.89 \log _{10}$ \\
\hline & & & WS (PCMX hand wash+62\% EtOH foam) & $4.16 \pm 0.91 \log _{10}$ \\
\hline & & & WS (non-antimicrobial hand wash $+70 \%$ EtOH AF gel) & $5.13 \pm 0.71 \log _{10}$ \\
\hline & & & WS (PCMX hand wash $+70 \%$ EtOH AF gel) & $5.22 \pm 0.60 \log _{10}$ \\
\hline & & Heavy food soil load & WS (non-antimicrobial hand wash + 62\% EtOH foam) & $4.11 \pm 0.48 \log _{10}$ \\
\hline & & & WS (Triclosan hand wash+62\% EtOH foam) & $3.97 \pm 0.45 \log _{10}$ \\
\hline & & & WS (PCMX and wash $+70 \%$ EtOH AF gel) & $4.60 \pm 0.52 \log _{10}$ \\
\hline & & & WS (Triclosan hand wash $+70 \%$ EtOH AF gel) & $4.51 \pm 0.43 \log _{10}$ \\
\hline & MNV & Organic soil load & Non-antimicrobial hand wash & $1.79 \pm 0.29 \log _{10}$ \\
\hline & & ( $5 \%$ fetal bovine serum) & ABHRs (70\% EtOH AF gel) & $2.60 \pm 0.41 \log _{10}$ \\
\hline & & & WS (non-antimicrobial hand wash + 70\% EtOH AF gel) & $3.19 \pm 0.31 \log _{10}$ \\
\hline & & & STW (70\% EtOH AF gel) & $4.04 \pm 0.33 \log _{10}$ \\
\hline
\end{tabular}




\begin{tabular}{|c|c|c|c|c|}
\hline \multicolumn{5}{|c|}{ Table 2 continued } \\
\hline \multirow[t]{16}{*}{ Gehrke et al. (29) } & FCV & Suspension & EtOH 50\% & $2.19 \log _{10}$ \\
\hline & & 30 s exposure & EtOH $70 \%$ & $3.55 \log _{10}$ \\
\hline & & & EtOH $80 \%$ & $2.19 \log _{10}$ \\
\hline & & & 1-Propanol 50\% & $\geq 4.13 \log _{10}$ \\
\hline & & & 1-Propanol 70\% & $\geq 4.06 \log _{10}$ \\
\hline & & & 1-Propanol 80\% & $1.90 \log _{10}$ \\
\hline & & & 1-Propanol 50\% & $2.31 \log _{10}$ \\
\hline & & & 1-Propanol 70\% & $2.35 \log _{10}$ \\
\hline & & & 1-Propanol 80\% & $1.35 \log _{10}$ \\
\hline & & Finger tips & EtOH $70 \%$ & $3.78 \pm 0.83 \log _{10}$ \\
\hline & & & EtOH 90\% & $2.84 \pm 0.64 \log _{10}$ \\
\hline & & & 1-Propanol 70\% & $3.58 \pm 0.92 \log _{10}$ \\
\hline & & & 1-Propanol 90\% & $1.38 \pm 0.33 \log _{10}$ \\
\hline & & & 2-Propanol 70\% & $2.15 \pm 0.50 \log _{10}$ \\
\hline & & & 2-Propanol 90\% & $0.76 \pm 0.19 \log _{10}$ \\
\hline & & & Water & $1.23 \pm 0.44 \log _{10}$ \\
\hline \multirow[t]{4}{*}{ Kampf et al. (36) } & FCV & Fingerpad & Reference alcohols (70\% Ethanol) & $1.45 \pm 0.41 \log _{10}$ \\
\hline & & Organic soil & Sterillium Virugard (95\% Ethanol) & $2.17 \pm 1.06 \log _{10}$ \\
\hline & & $5 \%$ fetal bovine serum & Sterillium Rub (80\% Ethanol) & $1.25 \pm 0.28 \log _{10}$ \\
\hline & & & Desderman N (75.1\% Ethanol) & $1.07 \pm 0.61 \log _{10}$ \\
\hline \multirow[t]{10}{*}{ Lages et al. (38) } & FCV & Finger tips & ABHRs (99.5\% Ethanol) & $1.00(30 \mathrm{~s})-1.30(2 \mathrm{~min}) \log _{10}$ \\
\hline & & $30 \mathrm{~s}$ and 2 min contact & Hand sanitizer (62\% Ethanol) & $0.50(30 \mathrm{~s})-0.55(2 \mathrm{~min}) \log _{10}$ \\
\hline & & periods & Antiseptic (91\% Isopropanol) & $0.00(30 \mathrm{~s})-0.43(2 \mathrm{~min}) \log _{10}$ \\
\hline & & & Antiseptic (70\% Isopropanol) & 0.67 (30s) - 0.55 (2 min) $\log _{10}$ \\
\hline & & & Antiseptic ( $3 \%$ Hydrogen peroxide) & 0.09 (30s) - 0.47 (2 min) $\log _{10}$ \\
\hline & & & $\begin{array}{l}\text { Antiseptic }(0.13 \% \text { Benzalkonium chloride } \\
+2 \% \text { lidocaine hydrochloride }\end{array}$ & $0.00(30 \mathrm{~s})-0.22(2 \mathrm{~min}) \log _{10}$ \\
\hline & & & Antiseptic (10\% Povidone-iodine) & $2.67(30 \mathrm{~s})-2.39$ (2 min) $\log _{10}$ \\
\hline & & & Antimicrobial soap (0.60\% Triclosan) & $0.25(30 \mathrm{~s})-0.50$ (2 min) $\log _{10}$ \\
\hline & & & Antimicrobial soap ( $0.115 \%$ Triclosan) & 0.42 (30s) - 0.17 (2 min) $\log _{10}$ \\
\hline & & & Water & $0.33\left(30 \mathrm{~s}^{\prime}-0.42(2 \mathrm{~min}) \log _{10}\right.$ \\
\hline Lin et al. (40) & FCV & Fingertips & Tap water & $1.22 \pm 0.86^{(1)} \log _{10}$ \\
\hline & & (Artificial feces) & & $1.97 \pm 0.68^{(2)} \log _{10}$ \\
\hline & & & Soap & $1.89 \pm 0.31^{(1)} \log _{10}$ \\
\hline & & & & $1.82 \pm 0.46^{(2)} \log _{10}$ \\
\hline
\end{tabular}


Table 2 continued

Antibacterial soap (Triclosan)

Hand sanitizers (62\% Ethanol)

Soap plus sanitizer

Soap plus nail brush

E. coli

Fingertips

Heavy food soil load

Tap water

Soap

Antibacterial soap (Triclosan)

Hand sanitizer (62\% Ethanol)

Soap plus sanitizer

Soap plus nail brush

Hand sanitizer (62\% Ethanol)

Antibacterial soap (0.5\% Triclosan)

Water rinse

Hand sanitizer (VF481 - 70\% Ethanol)

Hand sanitizer (VF447 - 70\% Ethanol)

Hand sanitizer (Endure 300 - 70\% Ethanol)

Hand sanitizer (Sterillium Virugard - 95\% Ethanol)

Hand sanitizer (Germstar Noro - 63\% Ethanol)

Hand sanitizer (Anios Gel 85 NPC - 85\% Ethanol)

Park et al. (46)
Suspension

(1 min exposure)
Hand sanitizer (79\% Ethanol - $\mathrm{pH} 7.1$ )

Hand sanitizer (72\% Ethanol - pH 4.1)

Hand sanitizer (72\% Ethanol - $\mathrm{pH}$ 2.9)

Hand sanitizer (67\% Ethanol - pH 7.4)
$1.65 \pm 0.19^{(1)} \log _{10}$

$2.26 \pm 0.42^{(2)} \log _{10}$

$0.43 \pm 0.47^{(1)} \log _{10}$

$0.86 \pm 0.55^{(2)} \log _{10}$

$1.85 \pm 0.69 \log _{10}(1)$

$2.13 \pm 0.93 \log _{10}(2)$

$0.41 \pm 0.49 \log _{10}(1)$

$2.54 \pm 0.57 \log _{10}(2)$

$1.29 \pm 0.53 \log _{10}(1)$

$1.18 \pm 0.14 \log _{10}(2)$

$1.09 \pm 0.51 \log _{10}(1)$

$1.18 \pm 0.24 \log _{10}(2)$

$1.26 \pm 0.47 \log _{10}(1)$

$1.45 \pm 0.59 \log _{10}(2)$

$1.16 \pm 0.63 \log _{10}(1)$

$1.31 \pm 0.68 \log _{10}{ }^{(2)}$

$1.59 \pm 0.45 \log _{10}(1)$

$1.85 \pm 0.84 \log _{10}(2)$

$2.54 \pm 0.54 \log _{10}(1)$

$3.07 \pm 1.18 \log _{10}(2)$

$0.27 \pm 0.12 \log _{10}(3)$

$0.34 \pm 0.22 \log _{10}(4)$

$0.67 \pm 0.47 \log _{10}(3)$

$1.10 \pm 0.49 \log _{10}(4)$

$0.58 \pm 0.37 \log _{10}(3)$

$1.38 \pm 0.49 \log _{10}(4)$

$3.74 \pm 0.85 \log _{10}$

$2.04 \pm 0.78 \log _{10}$

$1.49 \pm 0.62 \log _{10}$

$0.10 \pm 0.17 \log _{10}$

$0.11 \pm 0.22 \log _{10}$

$1.27 \pm 0.22 \log _{10}$

$0.1 \pm 0.2 \log _{10}(5)$

$0.0 \pm 0.2 \log _{10}(5)$

$0.1 \pm 0.1 \log _{10}(5)$

$0.2 \pm 0.2 \log _{10}{ }^{(5)}$ 
Hand sanitizer (0.1\% Triclosan - $\mathrm{pH} 3.0$ )

Hand sanitizer (0.2\% Triclosan - $\mathrm{pH} 3.0$ )

Hand sanitizer (4\% Chlorexidine - pH 5.4)
MNV

FCV
Hand sanitizer (79\% Ethanol - pH 7.1)

Hand sanitizer (72\% Ethanol - pH 4.1)

Hand sanitizer (72\% Ethanol - pH 2.9)

Hand sanitizer (67\% Ethanol - pH 7.4)

Hand sanitizer (4\% Chlorexidine - pH 5.4)

Hand sanitizer (79\% Ethanol - pH 7.1)

Hand sanitizer (72\% Ethanol - pH 4.1)

Hand sanitizer (72\% Ethanol - pH 2.9)

Hand sanitizer (67\% Ethanol - pH 7.4)

Hand sanitizer (0.1\% Triclosan - pH 3.0)

Hand sanitizer (0.2\% Triclosan - pH 3.0)

Hand sanitizer (4\% Chlorexidine - pH 5.4)

Hand sanitizer (45\% Ethanol)

Hand sanitizer (55\% Ethanol)

Hand sanitizer (90\% Ethanol)
Hand sanitizer (0.1\% Triclosan - pH 3.0)

Hand sanitizer (0.2\% Triclosan - pH3.0)

$0.0 \pm 0.3 \log _{10}(5)$

$0.0 \pm 0.1 \log _{10}$

$0.0 \pm 0.1 \log _{10}{ }^{(5)}$

3.01 $\pm 0.05 \log _{10}{ }^{(5)}$

$>3.6 \log _{10}{ }^{(6)}$

$0.0 \pm 0.5 \log _{10}(5)$

$>3.6 \log _{10}{ }^{(6)}$

$0.1 \pm 0.5 \log _{10}{ }^{(5)}$

$>2.6 \log _{10}(6)$

$1.9 \pm 0.4 \log _{10}(5)$

$2.0 \pm 0.2 \log _{10}(6)$

$0.4 \pm 0.3 \log _{10}(5)$

$1.1 \pm 0.1 \log _{10}{ }^{(6)}$

$0.0 \pm 0.2 \log _{10}(5)$

$0.2 \pm 0.1 \log _{10}(6)$

$0.0 \pm 0.1 \log _{10}(5)$

$0.0 \pm 0.3 \log _{10}(6)$

$0.8 \pm 0.7 \log _{10}(5)$ $0.0 \pm 0.2 \log _{10}(6)$

$0.7 \pm 0.9 \log _{10}(5)$

$0.0 \pm 0.2 \log _{10}(6)$

$0.9 \pm 0.8 \log _{10}(5)$

$>3.4 \log _{10}{ }^{(6)}$

$0.8 \pm 0.4 \log _{10}(5)$

$0.4 \pm 0.2 \log _{10}{ }^{(6)}$

$0.0 \pm 0.7 \log _{10}(5)$

$>3.4 \log _{10}(6)$

$0.2 \pm 0.2 \log _{10}{ }^{(5)}$

$>3.4 \log _{10}(6)$

$0.1 \pm 0.3 \log _{10}(5)$

$0.0 \pm 0.2 \log _{10}(6)$

Steinmann et al. (55) FCV

Suspension

$<1 \log _{10}$ 
Suspension (30s exposure)

MNV
Modified fingerpad
Hand sanitizer (45\% Ethanol)

Hand sanitizer (55\% Ethanol)

Hand sanitizer (90\% Ethanol)

Antimicrobial liquid soap (1\% Triclosan)

Antimicrobial liquid soap ( $4 \%$ Chlorexidine)

Antimicrobial liquid soap $(0.75-0.81 \%$ available iodine)

Hand sanitizer (45\% Ethanol)

Hand sanitizer (55\% Ethanol)

Hand sanitizer (90\% Ethanol)

Antimicrobial liquid soap (1\% Triclosan)

Antimicrobial liquid soap (4\% Chlorexidine)

Antimicrobial liquid soap $(0.75-0.81 \%$ available iodine

\section{Water}

Alcare (62\% emolliented ethanol foam)

Aquaress (nonantimicrobial soap)

Bacti-Stat soap $(0.1 \%$ Chlorhexidine gluconate,

0.50\% Didecyl dimethyl ammonium chloride, 5\%

Isopropanol)

Bioprep hand soap

Dettol (4.8\% 4-Chloro-3,5-xylenol, 9.4\% Isopropanol)

$70 \%$ Ethanol

Savlon (1.5\% Chlorhexidine gluconate, 15\% Cetrimide)

Scrub Stat IV (4\% Chlorhexidine gluconate, $4 \%$

Isopropanol)

Septisol (0.75\% Hexachlorophene)

Tap water

Triclosan hand soap (Triclosan 0.5\%)
$3 \log _{10}$

$5 \log _{10}$

$>5 \log _{10}$

$>4 \log _{10}$

$<1 \log _{10}$

$<1 \log _{10}$

$>2 \log _{10}$

4.25 $\log _{10}$

$3.94 \log _{10}$

$3.91 \log _{10}$

$3.42 \log _{10}$

$0.96 \log _{10}$

$4.62 \log _{10}$

$3 \log _{10}$

$89.27 \pm 4.38 \%$

$77.96 \pm 7.17 \%$

$92.04 \pm 4.02 \%$

$83.35 \pm 2.76 \%$

$88.63 \pm 5.38 \%$

$87.40 \pm 4.59 \%$

$90.91 \pm 5.08 \%$

$89.57 \pm 6.70 \%$

$88.60 \pm 5.36 \%$

$79.74 \pm 4.80 \%$

$91.29 \pm 4.47 \%$ 


\begin{tabular}{|c|c|c|c|c|}
\hline \multicolumn{5}{|c|}{ Table 2 continued } \\
\hline & & Whole hand & Alcare (62\% emolliented ethanol foam) & $86.17 \pm 4.28 \%$ \\
\hline & & & Aquaress (nonantimicrobial soap) & $91.39 \pm 2.65 \%$ \\
\hline & & & $\begin{array}{l}\text { Bacti-Stat soap ( } 0.1 \% \text { Chlorhexidine gluconate, } \\
0.50 \% \text { Didecyl dimethyl ammonium chloride, } 5 \% \\
\text { Isopropanol) }\end{array}$ & $94.56 \pm 5.75 \%$ \\
\hline & & & Bioprep hand soap & $81.44 \pm 1.59 \%$ \\
\hline & & & Dettol (4.8\% 4-Chloro-3,5-xylenol, 9.4\% Isopropanol) & $90.67 \pm 2.08 \%$ \\
\hline & & & $70 \%$ Ethanol & $86.92 \pm 1.63 \%$ \\
\hline & & & Savlon (1.5\% Chlorhexidine gluconate, $15 \%$ Cetrimide) & $86.53 \pm 3.44 \%$ \\
\hline & & & $\begin{array}{l}\text { Scrub Stat IV (4\% Chlorhexidine gluconate, } 4 \% \\
\text { Isopropanol) }\end{array}$ & $81.15 \pm 1.15 \%$ \\
\hline & & & Septisol (0.75\% Hexachlorophene) & $89.20 \pm 0.81 \%$ \\
\hline & & & Tap water & $81.57 \pm 4.55 \%$ \\
\hline & & & Triclosan hand soap (Triclosan $0.5 \%$ ) & $88.98 \pm 1.73 \%$ \\
\hline $\begin{array}{l}\text { Fendler \& Groziak } \\
(20)\end{array}$ & HAV & $\begin{array}{l}\text { Suspension } \\
\text { (30s exposure) }\end{array}$ & Purell Instant Hand Sanitizer (62\% Ethanol+emollients) & $1.25 \log _{10}$ \\
\hline \multirow[t]{7}{*}{ McCarthy (44) } & L. monocytogenes & Glove immersion (30s) & & \\
\hline & & PBS (PBS) and & 50 PPM Chloride (50ppm Sodium hypochlorite) & $5^{(\mathrm{PBS})}-3^{(\mathrm{CCW})} \log _{10}$ \\
\hline & & $\begin{array}{l}\text { Crab cooking water } \\
\text { (CCW) }\end{array}$ & 100 PPM Chloride (50ppm Sodium hypochlorite) & $5^{(\mathrm{PBS})}-3^{(\mathrm{CCW})} \log _{10}$ \\
\hline & & & Zep-I-dine ${ }^{T M}(25$ iodine $)$ & $3^{(\mathrm{PBS})}-3^{(\mathrm{CCW})} \log _{10}$ \\
\hline & & & Zepamine $A^{T M}$ (195 ppm active quaternaries) & $5^{(\mathrm{PBS})}->4^{(\mathrm{CCW})} \log _{10}$ \\
\hline & & & Zep $^{\mathrm{TM}}$ hand sanitizer (62\% Ethanol) & $4^{(\mathrm{PBS})}-3^{(\mathrm{CCW})} \log _{10}$ \\
\hline & & & Ultra Kleen (Peroxide-based powder $56 \mathrm{~g} / 3.8 \mathrm{~L}$ of water) & $5^{(\mathrm{PBS})}-5^{(\mathrm{CCW})} \log _{10}$ \\
\hline \multirow[t]{11}{*}{ Edmonds et al (14) } & E. coli & Hand test & & \\
\hline & & Moderate food soil load & Non-antimicrobial hand wash & $2.86 \log _{10}$ \\
\hline & & & STW (62\% Ethanol gel) & $2.84 \log _{10}$ \\
\hline & & & STW (62\% Ethanol foam) & $3.84 \log _{10}$ \\
\hline & & & $70 \%$ AF foam & $4.44 \log _{10}$ \\
\hline & & & STW (70\% AF foam) & $4.61 \log _{10}$ \\
\hline & & Heavy food soil load & Non-antimicrobial hand wash & $2.65 \log _{10}$ \\
\hline & & & STW (62\% Ethanol gel) & $2.69 \log _{10}$ \\
\hline & & & STW (62\% Ethanol foam) & $2.87 \log _{10}$ \\
\hline & & & $70 \%$ AF foam & $2.99 \log _{10}$ \\
\hline & & & STW (70\% AF foam) & $3.92 \log _{10}$ \\
\hline
\end{tabular}




\begin{tabular}{|c|c|c|c|c|}
\hline \multicolumn{5}{|c|}{ Table 2 continued } \\
\hline \multirow[t]{3}{*}{ Kampf et al. (37) } & E. coli & Hand test & Purell Instant Hand Sanitizer (62\% Ethanol) & $3.05 \pm 0.45 \log _{10}$ \\
\hline & & & Alcare plus (62\% Ethanol) & $3.58 \pm 0.71 \log _{10}$ \\
\hline & & & Water & $2.39 \pm 0.57 \log _{10}$ \\
\hline \multirow[t]{4}{*}{ Czerwinski et al. (10) } & E. coli & Suspension (15 s) & Hand sanitizer (Zylast Antiseptic, 76\% Ethanol) & $>6.14 \log _{10}(99.9 \%)$ \\
\hline & & & Water-based antiseptic lotion (Zylast-Lotion, $0.2 \%$ BZT) & $>6.14 \log _{10}(99.9 \%)$ \\
\hline & St. aureus & Suspension (15s) & Hand sanitizer (Zylast Antiseptic, 76\% Ethanol) & $>6.14 \log _{10}(99.9 \%)$ \\
\hline & & & Water-based antiseptic lotion (Zylast- $0.2 \%$ BZT) & $4.09 \log _{10}(99.9 \%)$ \\
\hline \multirow[t]{10}{*}{ Courtenay et al. (8) } & E. coli & Hand test & Cool water & $94.96 \%^{(7)}$ \\
\hline & & Heavy soil load & & $40.1 \%^{(8)}$ \\
\hline & & Ground beef & Warm water & $99.78 \%{ }^{(7)}$ \\
\hline & & & & $79.7 \%^{(8)}$ \\
\hline & & & Hand washing with plain soap & $99.98 \%^{(7)}$ \\
\hline & & & & $91.3 \%^{(8)}$ \\
\hline & & Hand test & Hand sanitizer B (62\% Ethanol+skin conditioner) & $94.44 \%{ }^{(7)}$ \\
\hline & & (not soiled hands) & Hand sanitizer c (62\% Ethanol+skin conditioner) & $96.33 \%{ }^{(7)}$ \\
\hline & & & Hand sanitizer $\mathrm{P}$ (62\% Ethanol+skin conditioner) & $96.07 \%^{(7)}$ \\
\hline & & & Hand sanitizer S (62\% Ethanol+skin conditioner) & $90.40 \%{ }^{(7)}$ \\
\hline \multirow[t]{2}{*}{ Fishler et al. (22) } & E.coli & Hand test & Hand washing with plain soap & $<2 \log _{10}$ \\
\hline & & & Antimicrobial soap ( $0.46 \%$ Triclosan) & $>3 \log _{10}$ \\
\hline \multirow[t]{8}{*}{ Gaonkar et al. (28) } & E. coli & $\begin{array}{l}\text { Suspension } \\
\text { (15 s exposure) }\end{array}$ & Octoxy hand rub & $7 \log _{10}$ \\
\hline & & $\begin{array}{l}\text { Pig skin method } \\
\text { (15 min post application) }\end{array}$ & Hand sanitizer (60\% EtOH +Phenoxyethanol+BZK) & Residual $4.96 \log _{10}$ \\
\hline & & & Hand sanitizer Avagards (61\% EtOH +CHG) & Residual $5.04 \log _{10}$ \\
\hline & & & Octoxy hand rub & Residual $0 \log _{10}$ \\
\hline & St. aureus & $\begin{array}{l}\text { Suspension } \\
\text { (15 s exposure) }\end{array}$ & Octoxy hand rub & $7 \log _{10}$ \\
\hline & & Pig skin model & Hand sanitizer (60\%EtOH +phenoxyethanol+BZK) & Residual $5.11 \log _{10}$ \\
\hline & & 15 min post application & Hand sanitizer Avagards (61\% EtOH+CHG) & Residual $5.68 \log _{10}$ \\
\hline & & & Octoxy hand rub & Residual $0 \log _{10}$ \\
\hline
\end{tabular}


Table 2 continued

\begin{tabular}{|c|c|c|c|c|}
\hline \multicolumn{5}{|c|}{ Table 2 continued } \\
\hline \multirow{4}{*}{ Paulson et al (47) } & E.coli & Hand test & Hand washing with plain soap & $2.12 \log _{10}$ \\
\hline & & & Antibacterial soap (PCMX) & $1.9 \log _{10}$ \\
\hline & & & Purell Hand sanitizer gel (62\% Ethanol) & $2.24 \log _{10}$ \\
\hline & & & WS (antibacterial soap+hand sanitizer) & $3.28 \log _{10}$ \\
\hline \multirow[t]{4}{*}{ Pickering et al. (48) } & E.coli & Hand test: & & \\
\hline & & Clean hand & ABHS & $2.33 \log _{10}$ \\
\hline & & Dirt-covered hand & ABHS & $2.32 \log _{10}$ \\
\hline & & Oil-coated hand & ABHS & $2.13 \log _{10}$ \\
\hline \multirow[t]{12}{*}{ Shintre et al. (54) } & E.coli & Suspension & $\begin{array}{l}\text { ZBF hand rub (60\% Ethanol+Farnesol+Benzethonium) } \\
\text { chloride }\end{array}$ & $>7 \log _{10}$ \\
\hline & E.coli & $\begin{array}{l}\text { Pig skin model } \\
\text { ( } 20 \mathrm{~m} \text { post application) }\end{array}$ & $\begin{array}{l}\text { ZBF hand rub (60\% Ethanol+Farnesol+Benzethonium } \\
\text { chloride) }\end{array}$ & Residual $3.26 \log _{10}$ \\
\hline & & & Avagard ${ }^{T \mathrm{M}}$ & Residual $4.70 \log _{10}$ \\
\hline & & & Prevacare $^{\mathrm{TM}}$ & Residual $5.65 \log _{10}$ \\
\hline & & & Triseptins & Residual $5.12 \log _{10}$ \\
\hline & & & Alcohol gel base & Residual $5.60 \log _{10}$ \\
\hline & St. aureus & Suspension & ZBF hand rub (Ethanol+Farnesol+Benzethonium chloride) & $>7 \log _{10}$ \\
\hline & & Pig skin model & ZBF hand rub (Ethanol+Farnesol+Benzethonium chloride) & Residual $1.89 \log _{10}$ \\
\hline & & (20 min post application) & Avagard $^{\mathrm{TM}}$ & Residual $4.94 \log _{10}$ \\
\hline & & & Prevacare $^{\mathrm{TM}}$ & Residual $5.16 \log _{10}$ \\
\hline & & & Triseptins & Residual $5.51 \log _{10}$ \\
\hline & & & Alcohol gel base & Residual $5.37 \log _{10}$ \\
\hline \multirow[t]{7}{*}{ Edmonds et al. (16) } & St. aureus & Suspension & Purell advanced hand sanitizer - $70 \%$ Ethanol gel & $\geq 5.8 \log _{10}$ \\
\hline & & (15 s exposure) & Purell advanced hand sanitizer - $70 \%$ Ethanol foam & $\geq 4.2 \log _{10}$ \\
\hline & & & Ethanol $70 \%$ & $\geq 4.2 \log _{10}$ \\
\hline & & $\begin{array}{l}\text { Hand test } \\
\text { After } 1^{(1 \mathrm{AA})} \text { and } 10 \\
\text { applications }{ }^{(10 \mathrm{~A})}\end{array}$ & $\begin{array}{l}\text { Purell advanced hand sanitizer - } 70 \% \text { Ethanol gel } \\
\text { Purell advanced hand sanitizer - } 70 \% \text { Ethanol foam }\end{array}$ & $\begin{array}{l}3.58^{(1 \mathrm{~A})} \log _{10}-3.50^{(10 \mathrm{~A})} \log _{10} \\
3.55^{(1 \mathrm{~A})} \log _{10}-3.48^{(10 \mathrm{~A})} \log _{10}\end{array}$ \\
\hline & & & Sterillium comfort gel (90\% ethanol gel) & $3.12^{(1 \mathrm{~A})} \log _{10}-1.80^{(10 \mathrm{~A})} \log _{10}$ \\
\hline & & & WHO recommended hand rub ( $80 \%$ Ethanol) & $3.07^{(1 \mathrm{~A})} \log _{10}-2.39^{(10 \mathrm{~A})} \log _{10}$ \\
\hline & & & WHO recommended hand rub ( $75 \%$ Ethanol) & $3.12^{(1 \mathrm{~A})} \log _{10} .2 .03^{(10 \mathrm{~A})} \log _{10}$ \\
\hline
\end{tabular}


Cutan Alcohol foam antiseptic hand rub (60\%Ethanol)

CHG wash + $60 \%$ alcohol gel product and $0.25 \%$

Hydroxypropyl cellulose

CHG wash $+0.25 \%$ Carbomer in alcohol solution

$3.48^{(1 \mathrm{~A})} \log _{10}-4.41^{(10 \mathrm{~A})} \log _{10}$

$2.99^{(1 \mathrm{~A})} \log _{10} 1.97^{(10 \mathrm{~A})} \log _{10}$

$2.83^{(1 \mathrm{~A})} \log _{10}-1.94^{(10 \mathrm{~A})} \log _{10}$

$2.48^{(1 \mathrm{~A})} \log _{10}-1.31^{(10 \mathrm{~A})} \log _{10}$

$2.86^{(1 \mathrm{~A})} \log _{10}-2.71^{(10 \mathrm{~A})} \log _{10}$
$2.88^{(1 \mathrm{~A})} \log _{10}-2.47^{(10 \mathrm{~A})} \log _{10}$

CHG wash + 0.25\% C10-30 Alkyl acrylate crosspolym

$3.26^{(1 \mathrm{~A})} \log _{10} 2.54^{(10 \mathrm{~A})} \log _{10}$

$\mathrm{CHG}$ wash $+0.25 \%$
alcohol solution

CHG wash + unthickened alcohol solution

$4.22 \log _{10}$

$4.12 \log _{10}$

CHG wash + Carbomer containing marketed Product A

CHG wash + Carbomer containing marketed Product B

CHG wash + Hydroxypropyl cellulose containing

marketed Product C

\begin{tabular}{|c|c|c|c|c|}
\hline \multirow[t]{9}{*}{ Fendler et al. (21) } & & Suspension & Purell Instant Hand Sanitizer (62\% Ethanol+emollients) & \\
\hline & Escherichia coli & (30 s exposure) & & $>5 \log _{10}$ \\
\hline & Escherichia coli $(0157 ; \mathrm{H7})$ & & & $>5 \log _{10}$ \\
\hline & L. monocytogenes & & & $>5 \log _{10}$ \\
\hline & St. aureus - methicillin-resistant strain. & & & $>5 \log _{10}$ \\
\hline & $\begin{array}{l}\text { St. aureus - vancomycin-tolerant- } \\
\text { methicillin-resistant }\end{array}$ & & & $>5 \log _{10}$ \\
\hline & Salmonella Enteritidis & & & $>5 \log _{10}$ \\
\hline & Salmonella Typhimurium & & & $>5 \log _{10}$ \\
\hline & Hepatitis A virus & & & $1.75 \log _{10}$ \\
\hline \multirow{3}{*}{$\begin{array}{l}\text { Charbonneau et al } \\
\text { (7) }\end{array}$} & Natural food flora & Hand test & Hand wash with non-medicated soap & $W \& S>W S>A B H S S$ \\
\hline & & Heavy soil load & Hand sanitizer (70\% Ethanol) & $A B H S s<W \& S<W S$ \\
\hline & & & WS (non-antimicrobial hand wash $+70 \%$ ETOH foam) & $W S<W \& S>A B H S S$ \\
\hline \multirow{3}{*}{$\begin{array}{l}\text { Wongworawat et al. } \\
\text { (61) }\end{array}$} & Natural flora & Hand test & Povidone-iodine scrub & Residual 2.5 CFU ${ }^{(\mathrm{WR})}-7.5 \mathrm{CFU}^{(\mathrm{R})}$ \\
\hline & & & Water-aided alcohol wash & Residual $0.5 \mathrm{CFU}^{(\mathrm{WR})}-1.0 \mathrm{CFU} \mathrm{(R)}^{(\mathrm{R})}$ \\
\hline & & & Water-less alcohol-chlorexidine lotion & Residual $0.0 \mathrm{CFU}^{(\mathrm{WR})}-0.0 \mathrm{CFU} \mathrm{(R)}^{(\mathrm{R})}$ \\
\hline
\end{tabular}


*Hand product: BZT, Benzethonium chloride; W \& S, water and soap; ABHRs, alcohol-based hand rubs; WS, Wash-sanitise; CHG, Chlorhexidine gluconate; STW, Sani-twice; W, PCMX, Para-chloro-meta-xylenol.

769 FCV, feline calicivirus; MNV, murine norovirus; HuNoV, human norovirus; HAV, Hepatitis A virus

$770 \quad{ }^{(1)}$ Artificial fingernails

$771^{(2)}$ Natural fingernails

772 (3) Standard American Society for Testing and Materials (ASTM) finger pad method with rubbing (ASTM) finger pad method

773 (4) Modified American Society for Testing and Materials (ASTM) finger pad method (with rubbing)

$774 \quad{ }^{(5)}$ Viral reduction estimated through RT-qPCR

(6) Viral reduction estimated through Plaque assay

${ }^{(7)}$ Bare hands

(8) Gloves

$778 \quad(\mathrm{R})=$ Hands with ring(s)

$779 \quad($ WR $)=$ Hands without rings 